
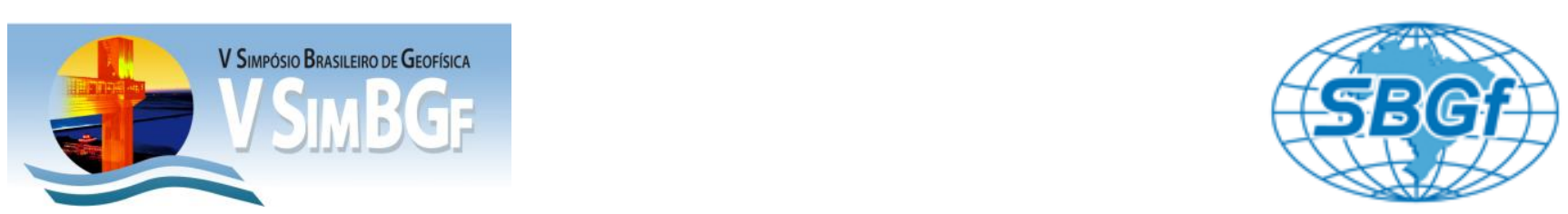

\title{
Processamento e interpretação de dados gamaespectrométricos do Complexo Granítico Caçapava do Sul
}

Neida llana Cardoso Rios*1

Mario Jesus Tomas Rosales ${ }^{1}$

${ }^{1}$ Universidade Federal do Pampa

\section{Copyright 2012, SBGf - Sociedade Brasileira de Geofísica}

Este texto foi preparado para a apresentação no V Simpósio Brasileiro de Geofísica, Salvador, 27 a 29 de novembro de 2012. Seu conteúdo foi revisado pelo Comitê Técnico do V SimBGf, mas não necessariamente representa a opinião da SBGf ou de seus associados. É proibida a reprodução total ou parcial deste material para propósitos comerciais sem prévia autorização da SBGf.

\section{Resumo}

The study area is located approximately $4 \mathrm{~km}$ southeast of Caçapava do Sul - RS. Geographically, bounded by latitudes $30^{\circ} 33^{\prime} 6.6$ "S $30^{\circ} 33^{\prime} 14.65^{\prime \prime} S$ and longitude $53^{\circ} 27^{\prime} 39.6$ "W and $53^{\circ} 27^{\prime} 30.2^{\prime \prime} \mathrm{W}$.

Geologically the study area is located in South Caçapava Granitic Complex ( $\approx 540 \pm 11 \mathrm{Ma}$ ), composed mainly of granodiorites, monzogranites and syenogranites.

The work was aimed at a combination of terrestrial geophysical of the gamaespectrometry and eletroresistivity in detail scale, in order to obtain results that contribute to the study of geological characterization of the region, by mapping the lithologic variations related to different facies for alteration the granite and weathered soil.

Introdução (Arial Bold, 9)

A região de Caçapava do Sul, onde se insere a área de estudo, localiza-se na unidade geotectônica denominada Escudo Sul-rio-grandense situada na porção meridional da Província Mantiqueira (Almeida et al., 1977). Esta área registra os eventos relacionados ao Ciclo Brasiliano/PanAfricano (Porada, 1979) no sudeste da América do Sul. A área de estudo localiza-se a aproximadamente $4 \mathrm{~km}$ a sudeste da cidade de Caçapava do Sul no estado do Rio Grande do Sul (RS), ocupando em superfície $400 \mathrm{~m}^{2}$ e delimitada geograficamente pelas latitudes -30.551833 e -30.554056 e longitudes -53.4612 e -53.4583 (Figura 1). Geologicamente se localiza no Complexo Granítico Caçapava do Sul (CGCS) composto principalmente por granodioritos, monzogranitos e sienogranitos (Nardi \& Bitencourt, 1989) e possui idade magmática em torno de 550 Ma (Sartori \& Kawashita, 1985; Leite et al., 1995). As estruturas de deformação planar e lineares dessa unidade revelam atuação de zonas de cisalhamento transcorrentes durante a geração destas rochas.

O trabalho visou à realização de um levantamento geofísico gamaespectrométrico, em escala de detalhe, cobrindo uma malha de pontos de medição com intervalo de amostragem de 20 metros, em conjunto com um levantamento de eletrorrestividade consistindo na realização de uma linha de Caminhamento Elétrico (CE) na porção central da área e a execução de uma Sondagem Elétrica Vertical (SEV) a fim de correlacionar os resultados.
A finalidade do trabalho é delinear os possíveis contatos entre o granito sem alteração (rocha sã) e a rocha alterada (solo intemperizado), verificar a profundidade do topo do granito (rocha sã) e identificar a presença de prováveis fraturas no granito.

Os dados gamaespectrométricos serão interpretados qualitativamente a partir dos mapas obtidos para os canais de $\mathrm{K}(\%)$, eU (ppm) e eTh (ppm) e os dados de eletrorresistividade para as técnicas de CE e SEV serão interpretados quantitativamente mediante técnicas de inversão.

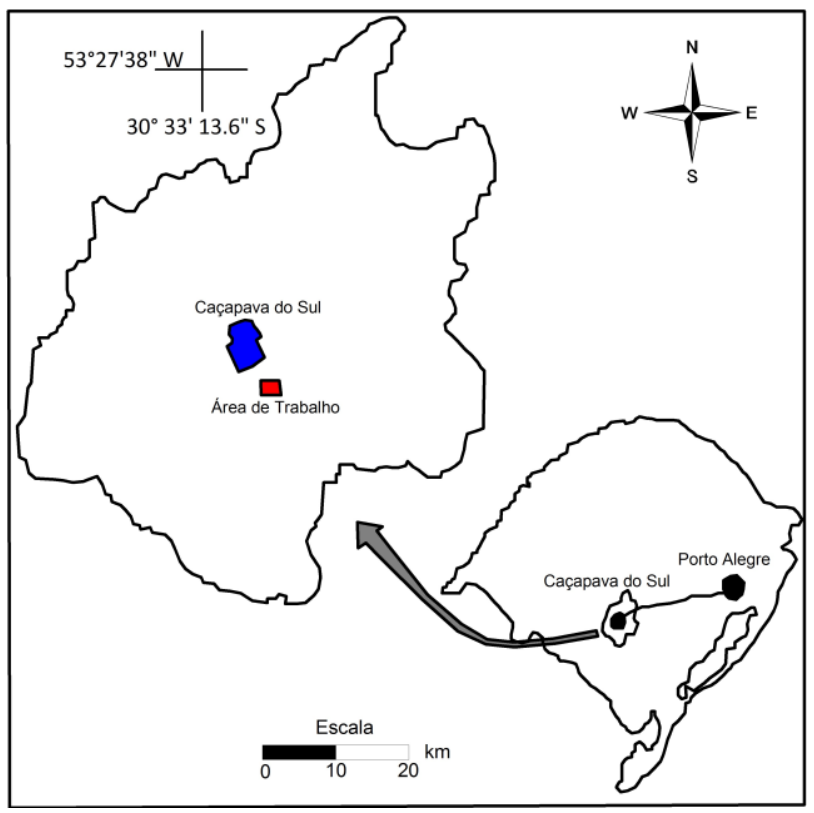

Figura 1 - Mapa ilustrativo da localização da área de estudo sudeste de Caçapava do Sul.

\section{Arcabouço Geológico da Área de Estudo}

Conforme pode observar-se no mapa geológico da Figura 2 , a área de estudo encontra-se no contexto geológico regional da Suíte Granítica Caçapava do Sul. Destacamse as fácies biotita granitóide e a leucogranitóide: a biotita granitóide acentua-se nas áreas de contato com as rochas metamórficas e também aparece foliado em áreas com presença de falhas contendo uma foliação que concorda espacialmente com a Sequência metamórfica Vacacaí ( $550 \mathrm{Ma}$ ). Morfologicamente, apresenta a característica de estar nas áreas rebaixadas do relevo composta por granitóides. Ocorre geralmente em afloramentos de matacões, é uma rocha granodiorítica a monzogranítica, de textura equigranular média a grossa 
(fina restrita), de cor acinzentada (não alterado) ou rosada (alterado).

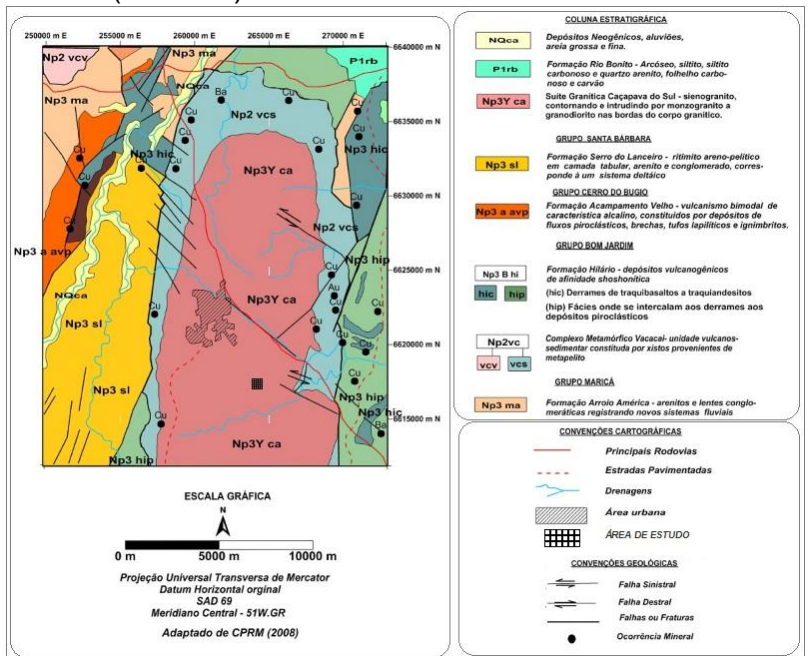

Figura 2 - Mapa geológico regional mostrando área de estudo (adaptado de CPRM, 2000).

Sua mineralogia é composta por feldspato potássio, quartzo e biotita. É facilmente afetado pelo intemperismo, o que torna a aparência da biotita granito muito semelhante à do leucogranito quando alterado.

As fácies leucogranitóide, assim como a biotita granito, ocorrem geralmente em afloramentos de matacões, é uma rocha comumente alterada, de tonalidade rosada, equigranular, com granulação média a grossa. É de composição monzogranítica a sienogranítica, com textura equigranular média. A mineralogia predominante é de feldspato potássico e quartzo.

As altitudes ortométricas caracterizam um relevo topográfico suavemente ondulado com variações de 394 a 410 metros na direção norte. O marco tectônico mostra a área inserida num contexto regional caracterizado pela presença de falhas com transcorrência sinistral seguindo um trend na direção NW-SE, alguns afloramentos de granito na área, mostram evidências de um alto grau de alteração e a presença de rochas fraturadas.

\section{Levantamento gamaespectrométrico e eletrorresistivo}

A Figura mostra a disposição dos dados gamaespectrométricos e eletrorresistivos na área de estudo.

A aquisição de dados geofísicos gamaespectrométricos foi realizada com gamaespectrômetro RS-230 BGO Super Spec (Figura 12), fabricado pela Radiation Solutions Inc - Canadá, composto por um detector de cristal de óxido germanato de bismuto (6,3 cu ins), pertencente à UNIPAMPA. Cobrindo uma malha de pontos com intervalo de amostragem de 20 metros, distribuídos em sete perfis orientados no sentido N-S e três perfis orientados no sentido $\mathrm{E}-\mathrm{W}$, cruzando os perfis orientados no sentido N-S.

O levantamento de eletrorresistividade foi realizado com um Eletrorresistivímetro analógico de fabricação nacional de marca TECTROL Equipamentos Elétricos e
Eletrônicos Ltda - SP - Brasil, pertencente a UNIPAMPA. Consistindo na realização de uma linha de Caminhamento Elétrico com arranjo dipolo-dipolo, espaçamento de 10 metros e uma Sondagem Elétrica Vertical, arranjo Schlumberger, com uma abertura máxima entre os eletrodos de corrente $(A B / 2)$ de 80 metros.

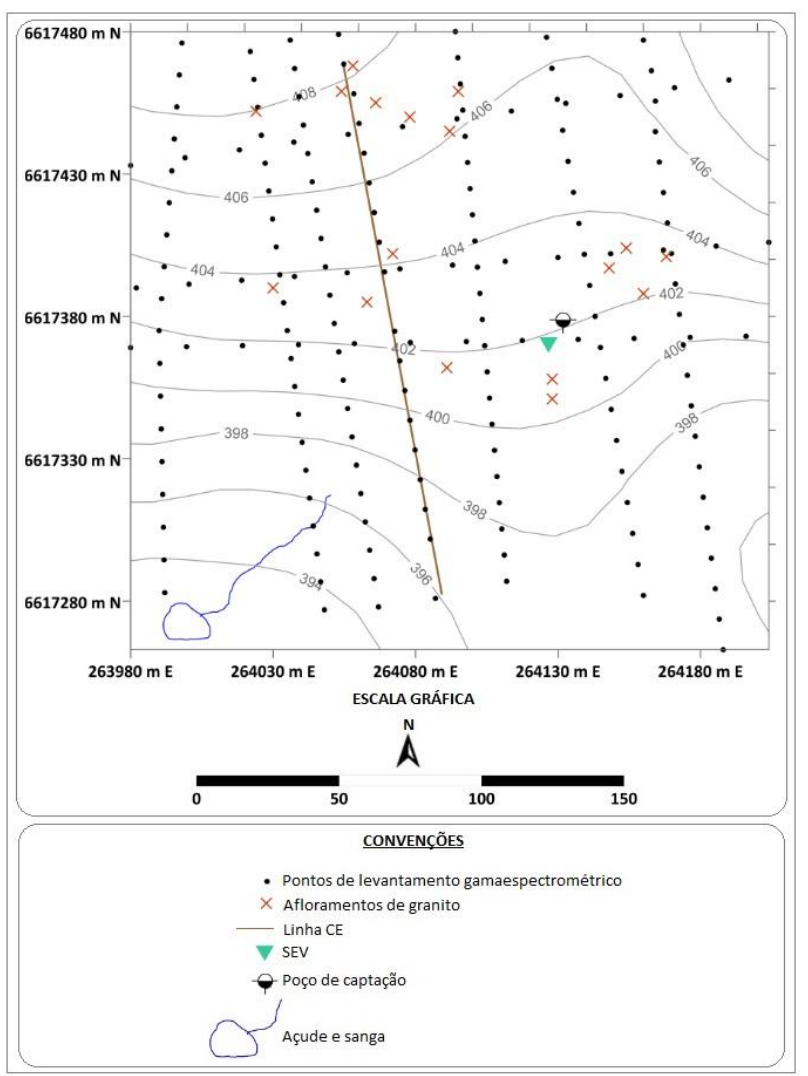

Figura 3 - Mapa esquemático dos dados do levantamento gamaespectrométrico e eletrorresistivo com curvas de altitude ortométrica na área de estudo .

\section{Interpretação de dados gamaespectrométricos}

Segundo Ủlbrich (2009) as regiões com afloramentos de rochas granitóides deveriam mostrar respostas gamaespectrométricas marcantes nos canais de potássio (K), tório (Th) e urânio (U), por esperar-se nessas rochas teores relevantes desses elementos e, em consequência, destaques positivos, frente às rochas vizinhas nãograníticas. Solos derivados de granitóides geralmente perdem cerca de $20 \%$ do seu conteúdo durante a pedogênese.

Analisando o mapa de contorno de potássio (\%) da área de estudo (Figura 4) observam-se quatro setores anômalos, com valores em torno de 3,4\%, esses setores estão associados à presença de feldspato potássico presente nos granito sem alteração que afloram na área. 


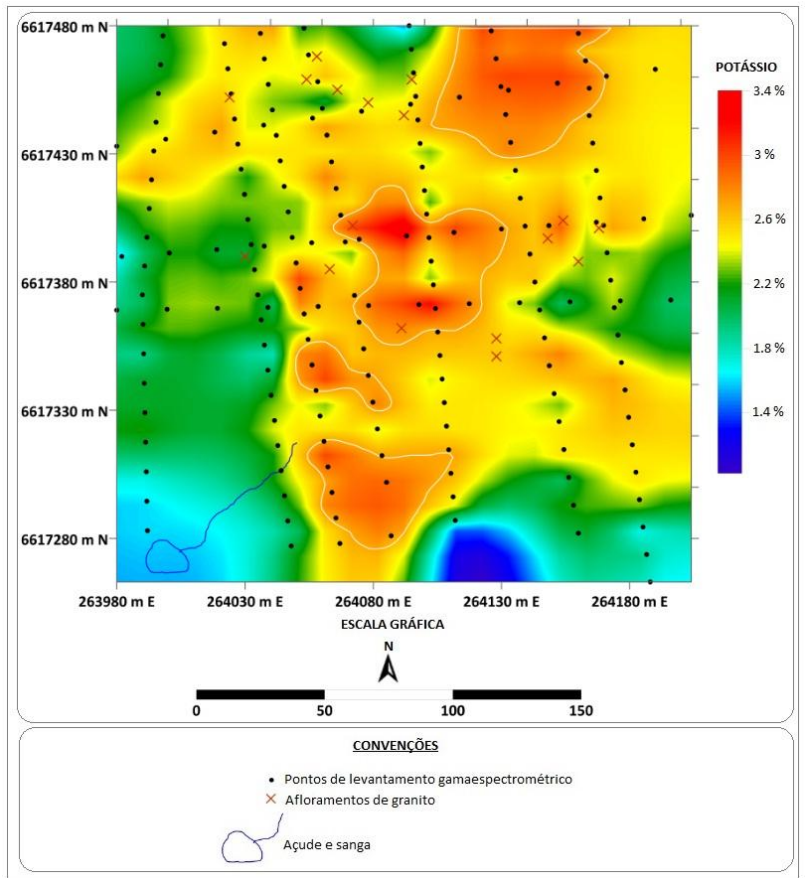

Figura 4 - Mapa de contorno de Potássio na área de estudo.

No mapa de contorno do Tório (ppm) da área de estudo (Figura 5) observa-se um comportamento homogêneo, não destacando valores anômalos.

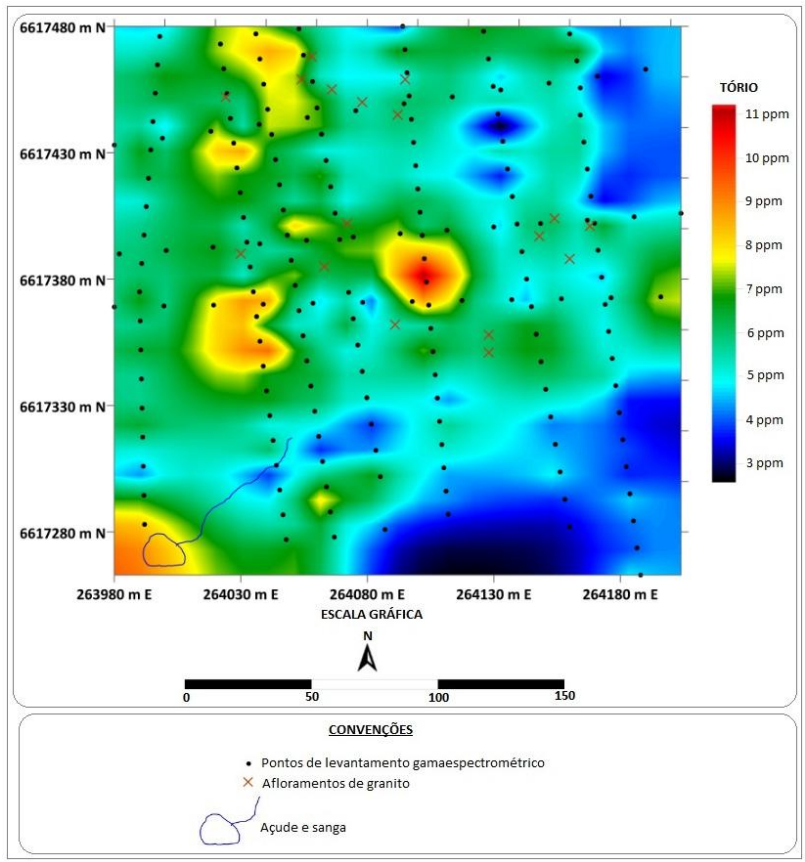

Figura 5 - Mapa de contorno do Tório na área de estudo.

O mapa de contorno do Urânio (ppm) da área de estudo (Figura 6), assim como no mapa de contorno do Tório, observa-se um comportamento homogêneo e não destaca valores anômalos.

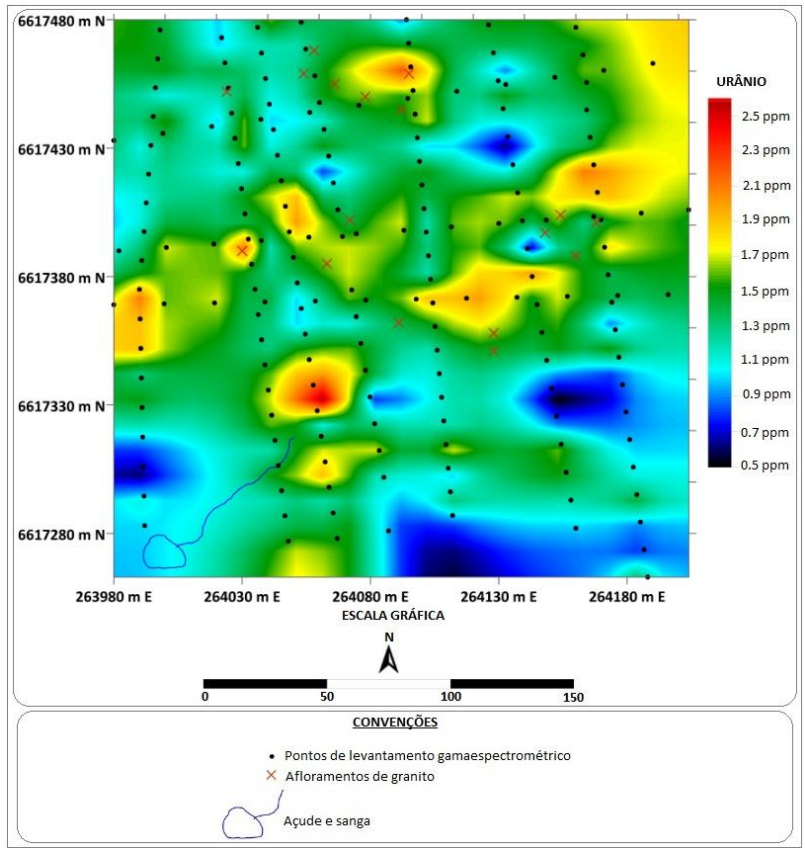

Figura 5 - Mapa de contorno de Urânio na área de estudo.

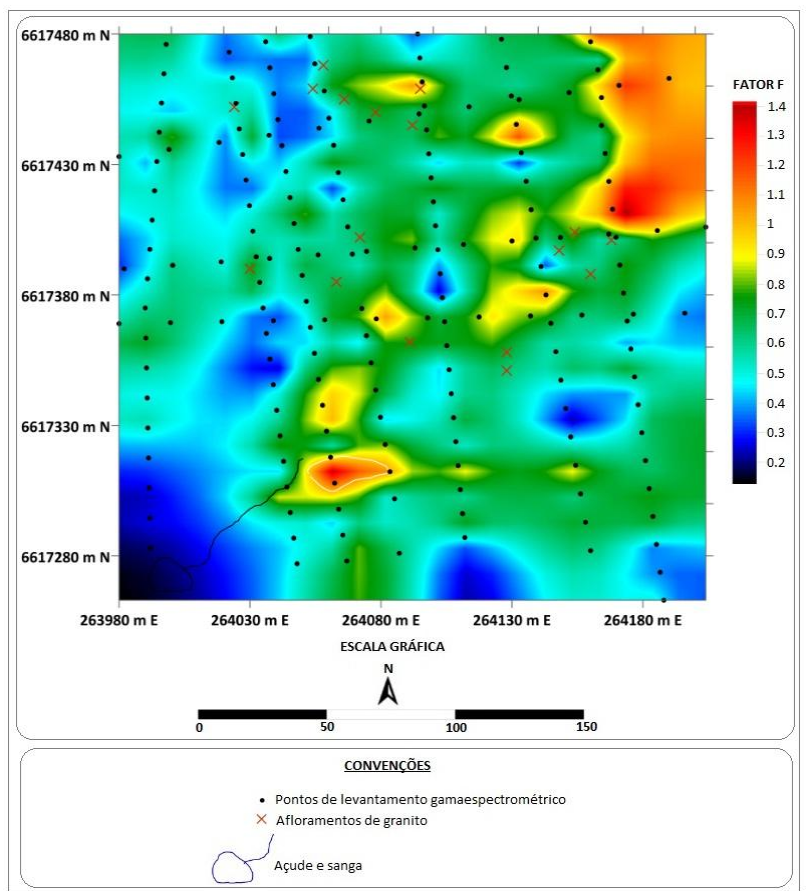

Figura 6 - Mapa de contorno do Fator $F$ na área de estudo.

O mapa obtido para o Fator F (Figura 6) é uma ferramenta para ajudar na interpretação dos altos anômalos correspondentes a os canais de $\mathrm{K} \mathrm{e} \mathrm{eU}$, devido ao fato do que o Th decorrente de sua baixa mobilidade geoquímica, permanece fixo durante o intemperismo e a pedogênese, então é de esperar que as zonas onde se apresentem valores altos do fator $F$ sejam zonas de alta mobilidade geoquímica onde as concentrações de 
potássio e de urânio sejam significativas motivo da movimentação desses radionuclídeos.

No mapa observa-se um alto anômalo do fator $F$ nas proximidades da sanga na área de estudo, provavelmente devido à movimentação do potássio e do urânio por percolação de fluidos.

\section{Análise espectral dos dados gamaespectrométricos}

Pode-se observar, dentre os canais estudados, que apenas o canal de potássio possui valores anômalos. Tentando aprofundar o estudo deste canal foi realizada a análise de alguns espectros inferidos pelo aparelho durante o levantamento.

Na figura 7, percebem-se pelo espectro valores anômalos de potássio. Este valor está associado a um alto topográfico sem afloramentos de granito.

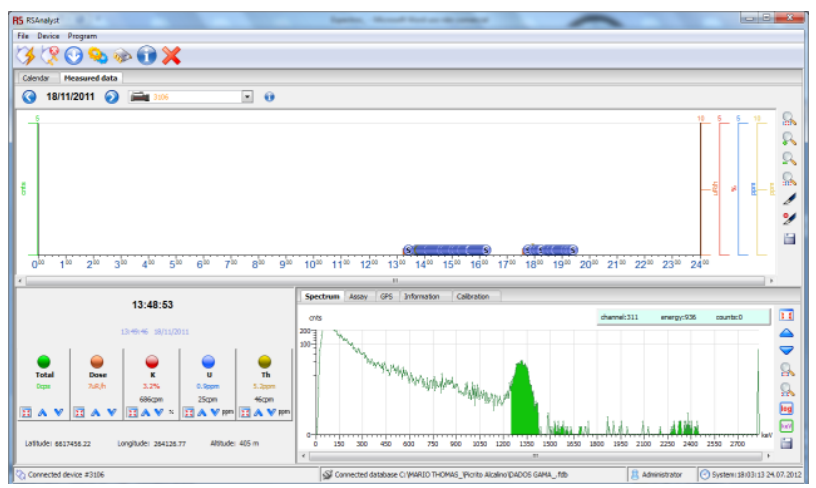

Figura 7 - Espectro com valor anômalo de potássio, associado a um alto topográfico sem afloramentos de granito.

Já na Figura 8, observa-se outra anomalia de potássio inferida pelo espectro. Essa medida foi realizada num alto topográfico, neste caso próximo ao granito aflorante.

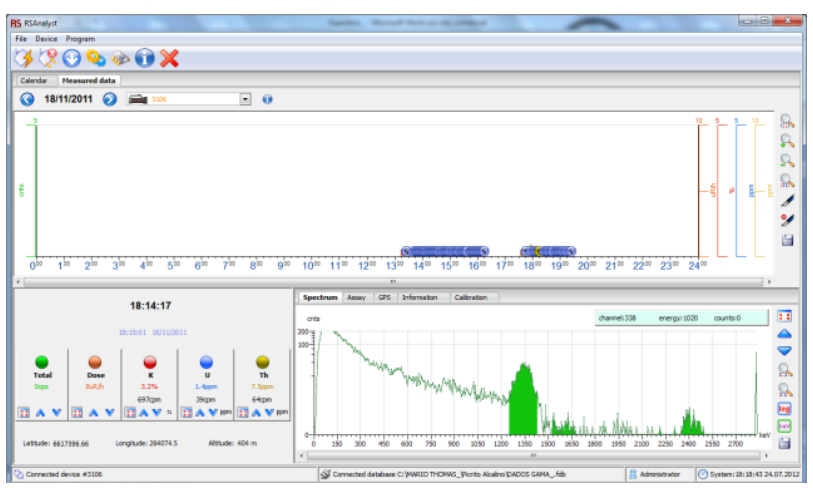

Figura 8 - Espectro com valor anômalo de potássio associado a um alto topográfico próximo a afloramentos de granito.

A chegada de energia dos espectros (Fig. 7 e 8) têm picos intensos, o que reflete a baixa umidade $e$ temperatura elevada $\left(\$ 37^{\circ} \mathrm{C}\right)$ no dia do levantamento dessas medidas. Levando em consideração apenas essas duas figuras, pode-se associar uma anomalia de potássio na área de estudo a altos topográficos.
Analisando o espectro (Fig. 9) pode-se concluir que o canal do potássio está abaixo da abundância média da crosta. Contudo, trata-se de uma medida realizada num alto topográfico da área de estudo sem granito aflorante assim como a Figura 7.

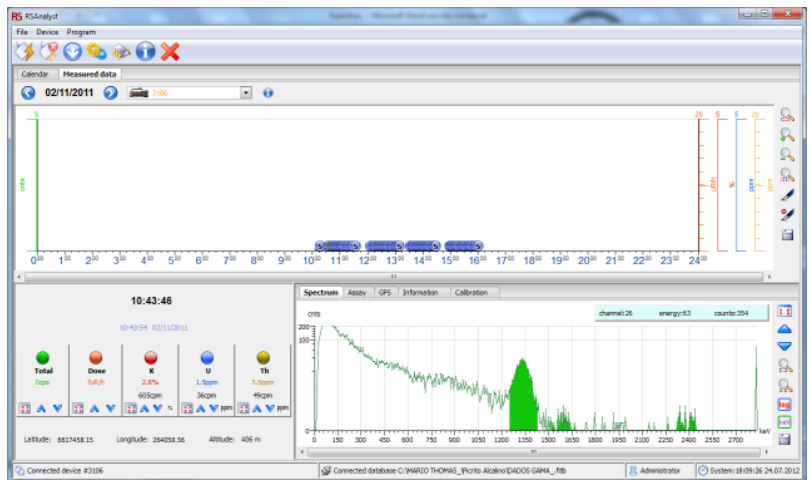

Figura 9 - Espectro com valor de fundo de potássio associado a um alto topográfico sem afloramentos de granito.

Para tentar entender a relação entre altos topográficos da área de estudo e o canal do potássio analisou-se a Figura 10, o espectro de uma medida realizada num alto topográfico com granito aflorante que possui um valor abaixo da média da crosta para o canal de potássio.

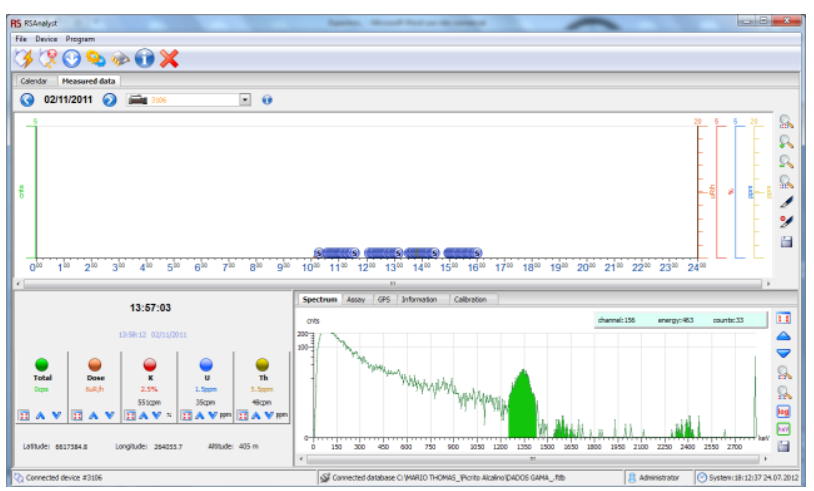

Figura 10 - Espectro com valor de fundo de potássio associado a um alto topográfico com afloramentos de granito.

A relação entre os espectros (Fig. 9 e 10) estão associados à chegada de energia, pode-se perceber que os picos são menos intensos que os picos das Fig. 7 e 8 e caracterizam a alta umidade e baixa temperatura $\left(\approx 24^{\circ} \mathrm{C}\right)$ no dia do levantamento dessas medidas.

A alta umidade atenua o sinal do gamaespectrômetro, o que pode explicar a baixa concentração de potássio inferida pelo aparelho num alto topográfico. 


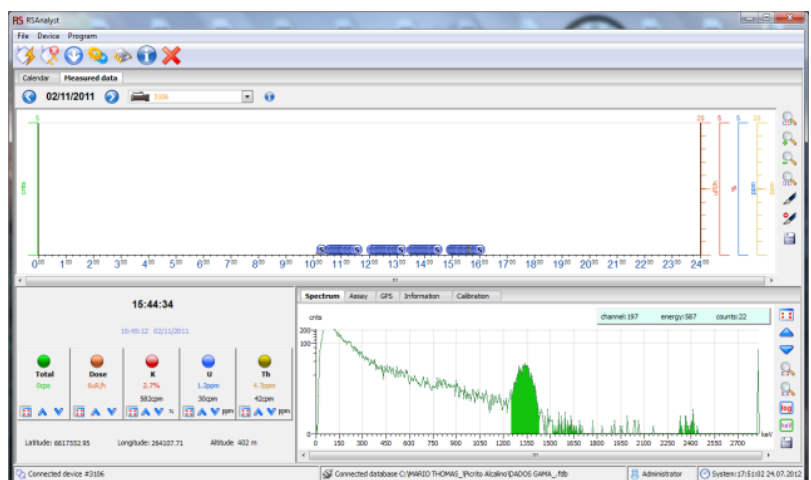

Figura 11 - Espectro com valor de fundo de potássio associado a um baixo topográfico sem granito aflorante.

Em baixos topográficos da área de estudo, a concentração de potássio está abaixo do valor médio da crosta, com ou sem afloramentos na área (Fig. 11).

\section{Interpretação dos dados de Caminhamento Elétrico}

A Figura 12 mostra o modelo obtido através do processo de inversão da linha de caminhamento elétrico, arranjo dipolo-dipolo, espaçamento entre os eletrodos de 10 metros, na área de estudo.

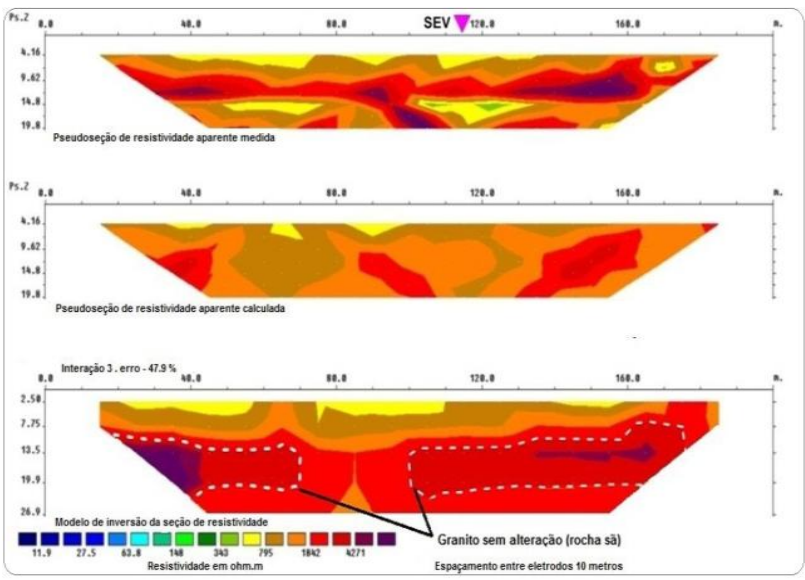

Figura 12 - Pseudo-seção de caminhamento elétrico na área de estudo.

Foi utilizado para a inversão dos dados do CE o programa Res2Dinv 3.57 da GEOTOMO software Sdn. Bhd.

A pseudo-seção do caminhamento elétrico mostra altas resistividades, na faixa de $1800 \mathrm{Ohm}=\mathrm{m}$, a partir de $9 \mathrm{~m}$ de profundidade, indicando o possível contato do topo do granito sem alteração (rocha sã). Na porção central da pseudo-seção, nota-se uma feição de menor resistividade, aproximadamente $800 \mathrm{Ohm}=\mathrm{m}$, associada provavelmente à presença de rocha alterada apresentando fraturas preenchidas com material argiloso.

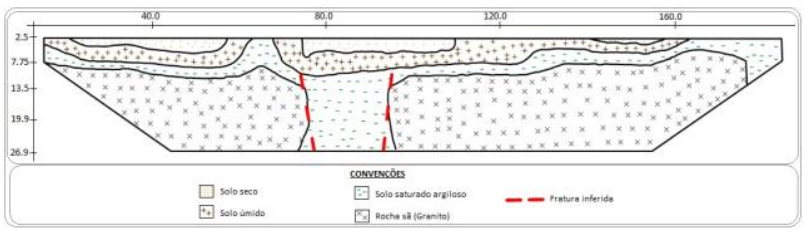

Figura 13 - Modelo geológico inferido a partir da pseudoseção de caminhamento elétrico.

O modelo geológico inferido a partir da interpretação da pseudo-seção (Figura 13) apresenta uma camada superficial com resistividades baixas, composta por um solo seco e material orgânico, na sequência observa-se uma camada com valores mais altos de resistividade composta por um solo mais úmido e argiloso (saprólito) posicionada acima do topo do embasamento rochoso (granito).

\section{Interpretação da curva SEV}

Foi utilizado para a inversão dos dados das SEVs o programa IPI2Win Version 3.0.1a. elaborado pela Universidade de Moscou, 2003.

A Figura 14 mostra o modelo gerado através do processo de inversão da SEV, arranjo Schlumberger, abertura máxima entre os eletrodos de 80 metros realizada, na área de estudo.

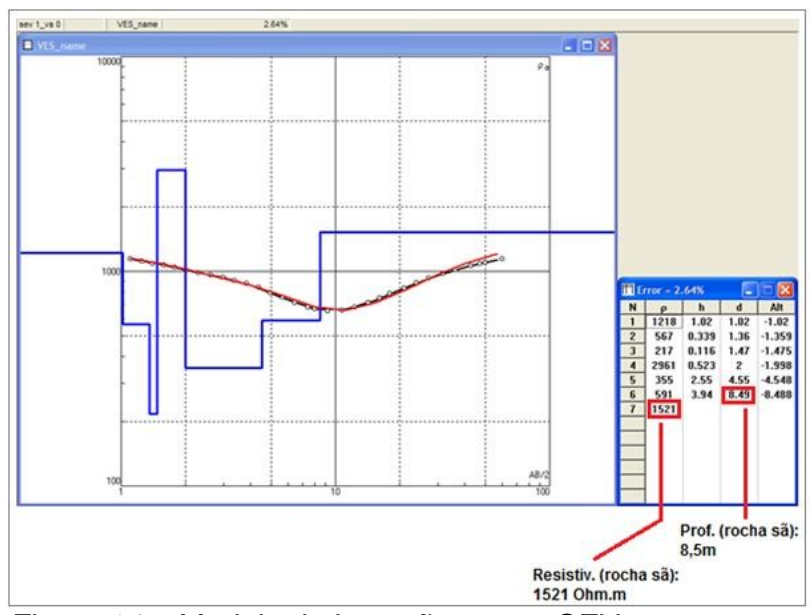

Figura 14 - Modelo de inversão para a SEV.

O modelo de inversão mostra-se compatível com a pseudo-seção do caminhamento elétrico, onde o topo do granito está a uma profundidade de aproximadamente $9 \mathrm{~m}$ de profundidade e têm uma resistividade na faixa de $1600 \mathrm{Ohm}=\mathrm{m}$.

\section{Conclusão}

Os resultados obtidos no trabalho se mostram consistentes do ponto de vista de interpretação geológico-geofísica dos dados geofísicos de gamaespectrometria e levantamento de eletrorresistividade com as técnicas de Caminhamento Elétrico e de Sondagem Elétrica Vertical.

Através da Eletrorresistividade com técnicas de Caminhamento Elétrico (CE) e de Sondagem Elétrica 
Vertical (SEV) foi possível verificar que o topo do granito (rocha sã) se encontra aproximadamente a nove (9) metros de profundidade apresentando valores de resistividade em torno de 1500 a 1800 Ohm.m.

Mediante o modelo de inversão da pseudo-secção elétrica a partir do Caminhamento Elétrico (CE), identificou a presença de prováveis fraturas no granito as quais apresentam continuidade em profundidade.

Delineou possíveis contatos entre o granito sem alteração (rocha sã) e a rocha alterada (solo intemperizado).

Os resultados do levantamento gamaespectrométrico revelam altos valores no canal de Potássio (K) associados à presença de variações das diferentes fácies de intemperismo do granito.

\section{Agradecimentos}

Agradecimentos a UNIPAMPA pela acessibilidade à realização desta pesquisa e a disponibilidade da instrumentação de campo.

Agradecimentos ao Prof. Dr. Mario Jesus Tomas Rosales pela orientação do trabalho.

\section{Referências}

BITENCOURT MF. 1983. Metamorfitos da região de Caçapava do Sul, RS: Geologia e relações com o corpo granítico. Atas do I Simpósio Sul-brasileiro de Geologia, Porto Alegre-RS, pp. 37-48.

BOBACHEV A; I MODIN; V. SHEVNIN. 2003 IPI2Win software. Versión 3.0.1a. Geoscan-M Ltd. Moscow State University. Russia.

CAMPONOGARA I, GOMES AAJ, SILVA SLJ \& FRANTZ CL. 2006. Potencial Hidrogeológico da região central do Rio Grande do Sul - XV congresso brasileiro de águas subterrâneas.

CPRM. COMPANHIA DE PESQUISA DE RECURSOS MINERAIS. 2000. Programa Levantamentos Geológicos Básicos do Brasil. Cachoeira do Sul, Folha SH.22-Y-A. Estado do Rio de Grande do Sul. Escala 1:250.000. Organizado por Carlos Alfredo Porcher e Ricardo da Cunha Lopes. Brasília.

DICKSON BL \& SCOTT KM. 1997. Interpretation of aerial gamma-ray surveys -adding the geochemical factors. AGSO Journal of Australian Geology \& Geophysics, Australia, 17(2): 187-200

FONTOURA XF. 2003. Aplicação da Sondagem Geofísica - Método de Elétrorresistividade - na locação de poços tabulares profundos. TECGEO Ltda; Departamento de Geofísica (Congresso Brasileiro de Águas Subterrâneas).

JACKSON, V. N., RAMOS, V.A..; TERRY, S. A.; ZUZEK, A. B. (1973). Projeto Aerogeofísico Camaquã, Estado Do
Rio Grande Do Sul. Porto Alegre: TEXAS INSTRUMENTS, DNPM/CPRM/CNEN, 1973. 208 p.

LEITE, J. A. D.; McNAUGHTON, N. J.; HARTMANN, L. A.; CHEMALE Jr., F. \& REMUS, M. V. D. 1995. SHRIMP $\mathrm{U} / \mathrm{Pb}$ zircon dating applied to the determination of tectonic events: the example of the Caçapava do Sul Batholith, Pedreira Inducal, Caçapava do Sul, Brazil.

NARDI, L. V. S. \& BITENCOURT, M. F. A. S. 1989. Geologia, petrologia e geoquímica do Complexo Granítico de Caçapava do Sul, RS. Revista Brasileira de Geociências, 19: 153-169

PORADA, H. 1979. The Damara-Ribeira Orogen of the Pan African-Brasiliano Cycle in Namibia (Southwest Africa) and Brazil as interpreted in terms of continental collision. Tectonophysics, 57: 237-265, 1979

RES2DINV Ver. 3.57. 2008. Geotomo Software Sdn Bhd, Malaysia. 